\title{
Using Mobile Phones in Pub Talk
}

\author{
Martin Porcheron*, Joel E. Fischer*, and Sarah Sharples ${ }^{\dagger}$ \\ *The Mixed Reality Laboratory \\ School of Computer Science \\ ${ }^{\dagger}$ Human Factors Research Group \\ University of Nottingham, UK \\ Faculty of Engineering \\ \{martin.porcheron, joel.fischer, sarah.sharples\}@ nottingham.ac.uk
}

\begin{abstract}
We present the findings from a study of how people interleave mobile phone use with conversation in pubs. Our findings, informed by ethnomethodology and conversation analysis, unpack the interactional methods through which groups of people in pubs occasioned, sustained, and disengaged from mobile device use during conversation with friends. Fundamentally, the work that is done consists of various methods of accounting for mobile device use, and displaying involvement in social interaction while the device is used. We highlight multiple examples of the nuanced ways in which interleaving is problematic in interaction, and relate our findings to the CSCW and HCI literature on collocated interaction. We conclude by considering avenues for future research, and discuss how we may support or disrupt interleaving practices through design to overcome the highlighted interactional troubles.
\end{abstract}

\section{Author Keywords}

mobile devices; smartphones; third place; bar; collocated interaction; ethnomethodology; conversation analysis.

\section{ACM Classification Keywords}

H.5.3. Group and Organization Interfaces: Computersupported cooperative work; H.5.m. Information Interfaces and Presentation (e.g. HCI): Miscellaneous.

\section{INTRODUCTION}

Mobile phones have become truly ubiquitous and have permeated each and every walk of life; they accompany us throughout the day, from first thing in the morning to last thing at night. However, in conjunction with the meteoric rise in mobile device ownership, researchers have begun to highlight a number of growing pains such as the impact on social order when using technology during collocated interactions [30, 40, $44,52]$. Given the increased prevalence of mobile devices, an arguably important yet understudied research question we seek to address in this paper is how do individuals conduct the interactional work of interleaving mobile device use with their ongoing conversation?

Permission to make digital or hard copies of all or part of this work for personal or classroom use is granted without fee provided that copies are not made or distributed for profit or commercial advantage and that copies bear this notice and the full citation on the first page. Copyrights for components of this work owned by others than the author(s) must be honored. Abstracting with credit is permitted. To copy otherwise, or republish, to post on servers or to redistribute to lists, requires prior specific permission and/or a fee. Request permissions from Permissions@acm.org. CSCW' 16, February 27-March 02, 2016, San Francisco, CA, USA Copyright is held by the owner/author(s). Publication rights licensed to ACM. ACM 978-1-4503-3592-8/16/02 . \$15.00

DOI: http : //dx . doi . org/10.1145/2818048.2820014
Existing work within the HCI community has highlighted both how mobile devices provide eminent support for distributed interactions and the power of mobile devices to assist in connecting non-collocated individuals [19, 27]. Moreover, mobile devices have been purposed for use in collaborative task situations amongst collocated groups [24, 35, 39]. However, in spite of considerable progress in mobile technology, critical voices from academic [53] to popular [55] writers have pointed out the ways in which mobile devices may isolate people from one another in social situations. On the other hand, socio-technical studies have shown people are skilled at interleaving mobile device use and social interaction, for example in a living room setting [47] and in a collaborative photo-taking setting [16].

While we are not interested in making moral judgements, we are interested in how exactly people accountably organise mobile device use in casual social settings. We conducted fieldwork in situations where friends devote time to socialising with each other in a face-to-face manner in a setting that epitomises the very definition of a place that is both casual and social - the pub. In this work, we identify the naturally accountable methods through which individuals make use of mobile devices during focused encounters [20] in the pub.

Through our study, informed by ethnomethodology and conversation analysis, we contribute two key findings to HCI and social computing: firstly, we identify the interactional methods through which mobile devices are introduced to, sustained in, and disengaged from conversations; and secondly we draw out the machinery of interaction [48] members employ to manage mobile device usage within collocated interactions. When combined, these contributions allow us to discover a number of interactional troubles, and hypothesise ways for how future technology could be developed to better support focused interactions in such casual social settings.

This paper begins by reviewing and positioning the literature in relation to our work and then we explain our analytic orientation and why we feel that pubs are an interesting setting for this research. We go on to present our findings that unpack the interactional methods through which mobile device use is interleaved with conversations. We present interactional fragments as vivid exhibits [10, p. 112] of how this interactional work is accomplished, and then discuss the ostensibly problematic nature of interleaving practices in interaction and link our findings with existing literature on related studies. Finally, we describe how these considerations can be incorporated into future design and research of both hardware and software based technologies. 


\section{RELATED WORK}

We review literature that has contributed to greater understanding of the pervasive nature of mobile devices, and their use in public and collocated settings.

\section{Mobile Devices and Space}

We begin by highlighting a substantive body of work investigating how to better deliver mobile notifications to individuals in face of the potentially disruptive nature of such interruptions $[11,14,17,33]$. The pertinence of this is that as individuals gather to socialise, device use can impact an individual's orientation to the space and co-inhabitants. In relation to how we now make use of devices anywhere and everywhere we go, Geser [19] states that "a new, more fluid culture of informal social interaction therefore can emerge". Furthermore, Campbell [5] highlights how "mobile communication around copresent others (...) personalizes the communal experience of being in that space"; which also supports work by others of the practice of using technologies to create private spaces in public places (e.g. $[1,56])$. In linking these fields of work, it can be seen that how people manage both the virtual and co-present interactions is of great interest to researchers examining the disruptive nature of technology-mediated interruptions. This approach bears the ultimate goal of ameliorating the overall experience of the mobile device user, and their orientation to both the space and co-present others.

Mobile devices also present a method for owners to remain in touch with their extended network. This raises expectations that we should quickly respond to our contacts from our extended network, just as we expect them to respond [1]. This immediacy provides users the sense of being "always connected, to be accessible at all times and places" [45]. Given the desire, or in some cases, compulsion, to remain connected, there is a need to understand the complex factors around the comanagement of both the virtual and physical interactions. This is, in part, due to the relative ease for individuals to retreat to their phone and "shield oneself from wider surroundings" [19]. Thus, the fact that mobile devices are always connected, and that devices can provide notifications at any point, a situation becomes engendered where virtual interactions can potentially rub up against collocated physical interactions. As opposed to attempting to reduce device usage in such instances, we are interested in guiding how the impact of this use can be considered in design by understanding the nuanced ways in which the device use occurs.

\section{Mobile Devices in Public Settings}

The use of mobile devices in public settings has been well documented in literature for a variety of purposes, from how an iPod allows an individual to reshape their experience of time and space [4] to how individuals use new technologies such as cellphones to adapt their social perspective [26, 42, 45]. Mobile devices possess the advantage of portability and flexibility that allows for their greater use within many different settings, including conversation. Certainly, the increased portability and functionality of mobile devices seems to be encouraging their use in such settings, within the implications of usage in public spaces derided as annoying or rude by co-present others [1, 26]. For example, Humphreys et al. [28] highlight findings that suggest that the ease of using the 'mobile Internet' potentially exacerbates the problem of "mis-prioritizing communication through their mobile device over and above face-to-face communication". Additionally, in relation to the use of mobile devices in public places, and in particular pubs, $\mathrm{Su}$ and Wang [53] state that technology can "threaten conversation by creating the present-but-absent, anti-social, and app-addicted patron". Finally, beyond merely being a distraction, mobile devices can also be utilised as a tool to avoid co-present others, or even facilitate the avoidance of sociality and meeting people in public places altogether [27], although we note that such observations are less impactful in our work given we are interested in post-congregation for the purpose of meeting and socialising.

\section{Mobile Devices in Collocated Interactions}

CSCW literature contains many use cases of collocated mobile device use such as photo sharing $[9,12]$, video watching [41], and collaborative searching tasks $[6,8]$, often involving interaction with additional screens or multiple mobile devices [2, 35]. This work demonstrates the beneficial uses of technology in collocated interactions, and this refutes - or at least qualifies - simplistic popular views that mobile devices create "social isolation" [53].

However, there is also a gap in the literature around the ways in which such interactions are occasioned, and how individuals co-manage device use and social interactions. Furthermore, not all interactions are likely to engender collaborative work that all members can engage in. Our interests lie in how individuals manage the use of these 'always connected' devices in conversation, the observable-and-reportable actions of those in the setting, and just how device use is embedded in the social order enacted in and throughout ongoing interaction. Thus, we are interested in attempting to understand the specific interactions that occur, and how mobile devices become occasioned during conversation. Our aim with this research is to fundamentally examine the detail of how devices are brought in and out of conversation. Insights in this space have the potential to help designers in the goal of creating more fluid device interactions for multiple users, allowing others to take into account the uncovered interactional practices in their own future work.

\section{STUDY APPROACH}

We were motivated by rhetoric around the impacts of mobile device use in everyday situations, and especially when friends are socialising. Therefore, our focus is on casual social settings; such settings, termed by Oldenburg [43] as 'third places', can be defined as places where individuals purposefully co-inhabit with the purpose of socialising in a relaxed and unimposing environment and where conversation is the main activity. This stance also does not restrict us in choosing a venue that is exclusively public or private. For example, our experience teaches us that it is common for groups of friends to meet in public plazas, as well as cafés or restaurants. The purpose of the gathering in such a venue is to socialise, with a "common code of conduct" that is both informal but still provides a guidance of behaviour [32]. 


\section{Research Setting}

In choosing a setting to conduct our fieldwork, we gave consideration to a variety of venues including cafés and public squares, however, we opted for a local pub. We chose a pub for a number of reasons, some logistical and others sentimental. The devotion of spending leisure-time in pubs and bars with friends is a popular British pastime; pubs typically open early and close late, many provide food and drink, and they serve as an environment suited to relaxing and conversing with others. In describing her observations of English culture, anthropologist and popular social science writer Kate Fox describes pubs as "a central part of English life" [18] and others have also highlighted pubs "as a social centre for the community" [7]. These descriptions are also reflected in official statistics [51], which state that $48 \%$ of people aged 16 and over would choose to go to a pub or bar in their free time; this figure is even higher for younger age groups.

Finally, from our own experience we knew the pub setting would allow us to observe naturally occurring interactions around device use in an environment in which mobile phone use is common, and sometimes at the derision of co-present others. We concluded that pubs are a suitable natural environment for the study of how people interleave mobile device use during conversations in a casual social setting.

\section{Methodology}

We performed an ethnomethodological study with a focus on revealing the interactional methods members employ to accomplish the work of interleaving mobile device use with ongoing conversation. We collected video and audio recordings as part of our approach in an effort to allow us to identify the embedded nature of mobile devices, and the subtly observable actions exhibited by members within the setting through video analysis. Overall, the ethnographic record comprises video recordings of the interaction, field notes and individual questionnaires completed by members, and each group also participated in an informal semi-structured interview.

Questions were asked after the 'observation phase' as an interview so as not to interrupt the conversation. The purpose of the interview was to contextualise the observations and gain an insight into the participant's perceptions of mobile device use in conversation. Participants also completed a short questionnaire after the observation phase to allow us to gather information on the technology they owned. Given the evolving landscape of mobile technologies, this acted as a point of curiosity to understand the present situation.

To analyse our corpus of collected data, we conducted video analysis drawing on ethnomethodology and conversation analysis [21, 22], and interaction analysis [29]. Firstly, shortly following data collection, the corpus of data was catalogued and indexed to identify episodes in which mobile device use occurred. We used timestamps and descriptive language to construct a record of the interactions that took place, which allowed us to iteratively re-examine prior data with relative ease. This was in order to aid the discovery of the observableand-reportable actions performed by the members within the setting and to help us gain an overall impression of the data collected across all the sessions.
We identified a total of 51 episodes of mobile device use in the sessions (some of which were overlapping), with episodes ranging from a few seconds to a few minutes in length. We then performed a substantive review of the episodes to examine the interaction, honing in on episodes that represented observable-and-reportable intersections of mobile device use and conversation for a more in-depth analysis. This process required the transcription of both verbal (i.e. talk) and nonverbal (e.g. gestures and gaze actions). We chose to ignore situations where, for example, mobile devices were used merely as timepieces for a split-second.

Following multiple iterative reviews, we engaged in a collaborative 'data session' to allow colleagues to watch, review, and comment on collected video to help contribute towards this analysis. Our observations and commentary were provided along with transcripts of the clips.

\section{Study Procedure and Participants}

After finding a pub that agreed to host our research, participants from the local University were recruited using email and word-of-mouth. Participants were recruited as groups of friends who felt they would "typically go to the pub with each other" and were willing to be observed for their 'behaviours around mobile devices' within a pub. In total, eleven participants took part (in three separate groups); seven of the participants identified as female, with the remaining four identifying as male. Each group had at least one female and one male, although this was by chance and not intention. Of the recruited participants, four were 18-23, five were 24-29, and two were 30-39. Fieldwork was conducted over a three-month period in the UK, with studies taking place at a time agreed with the recruited participants. The study was approved by the University's School of Computer Science Ethics Committee and we reimbursed all participants with an online shopping voucher for their time spent during the study.

On the day of the visit, a researcher accompanied the group to the pub, set up the recording equipment and then took on the role of participant observer. In addition to video and audio recordings, field notes were taken, but not until after the session so as not to distract the participants. We positioned two cameras carefully to capture the participants around a table, while limiting the recording of others in the pub. Studies took place during the mid-to-late afternoon at times agreed to be suitable by all and during normal opening hours. Although we note that drinking alcohol was by no means a requirement for the study, most participants chose to do so. Recording sessions typically lasted between 60-90 minutes, depending on the natural course of the pub talk.

It was common for participants in our observations to have their phones visible on the table at some point, with six members maintaining the presence of the device on the table throughout the observation (others kept their phones in their pocket or bag during non-use). Through the questionnaire, we asked participants about which technology they owned: all participants owned smartphones, and had them present, a majority (seven) also owned tablets (although six of these relied on a Wi-Fi connection), however none had a tablet with them, and there were no smartwatches. 


\section{FINDINGS}

In order to unpack the orderly ways in which members use mobile devices in pubs, we orient to the temporal sequentiality in which device use is begun, carried out, and ended in the course of conversation. We adopt this common approach as it brings into focus the internal structure of the process through which the work is managed [29].

Thus, following the ethnomethodological focus on the observable-and-reportable actions of members within the setting, we focus on the following key sequences of activity conducted by members:

- Occasioning: The ways in which mobile device use is occasioned in and through interaction, including the talk and embodied actions that lead up to the usage (if observable);

- Sustaining: How the mobile device usage is sustained with respect to both the role of the mobile device use in the conversation, and the actions of the members within the broader context;

- Disengaging: The ways in which the mobile device is disengaged from, either temporarily or (semi-)permanently.

Each of these activities can take multiple forms, and in the following sections we present each stage as well as a number of selected relevant episodes as 'fragments' of our data that provide the vivid exhibits of the work conducted by members. In so doing, we also scrutinise the interactional resources that members employ to accomplish this work. Interactional resources include talk, body movement and orientation, and gestures [37]. Furthermore, we can comment on situations where mobile devices provided notification chimes, or displays turned on, as this was observable within the setting. We provide numbers in relation to occurrences as descriptive indices into our qualitative data corpus.

All transcripts are given like this, using the verbal notation by Heath et al. [22], with the addition of non-verbal actions within double-parentheses where relevant, in addition to emphasis, volume (LOUD, ${ }^{\circ}$ quiet ${ }^{\circ}$ ) and pauses (.) between words. We provide imagery that depicts the embodied actions of members. All names and identifiable information are entirely fictional.

\section{Occasioning}

In discussion of the use of artefacts in workplaces, Hindmarsh and Heath [23] discuss how "objects, and their occasioned determination, implicate specific courses of action by particular participants". The knowledge of how objects, specifically mobile phones in our case, are occasioned is fundamental in understanding the later behaviours of members during mobile device usage. In our work, the usage of mobile devices was occasioned in a number of ways; occasioning of the mobile device usage is constituted of the actions of those within the setting that lead to at least one member making use of their mobile device. We identified two key forms of mobile device usage occasioning within the context: occasioning that was related to the conversation, and occasioning which was ostensibly unrelated to the conversation.

\section{Occasioning In and Through the Conversation}

The purpose of leisure-time socialising is that of conversing and spending time with friends in a group. Through the actions of the members within the group, mobile devices can become occasioned in a number of different ways. In our work, perhaps unsurprisingly given the nature of the context, we found that in $47 \%$ of occasioning instances, occasioning of device use was related to the conversation. That is, nearly half of the time, a member chose or acquiesced to use their device in and through the conversation.

Firstly, we present the episode given in Fragment 1 as an exhibit of how readily mobile device use is occasioned. The mobile phone usage in this episode is as a result of confusion amongst the members within the setting over what the exact definition of a ballad is. In this episode, we join four friends: Dayna, Jenna, Cally, Roj, and the researcher Philip, as Dayna offers the definition that she believes to be the case. Before this discussion, Jenna has her (locked) mobile phone on the table, while the others in the group all have their mobile phones either in their bags or pockets.

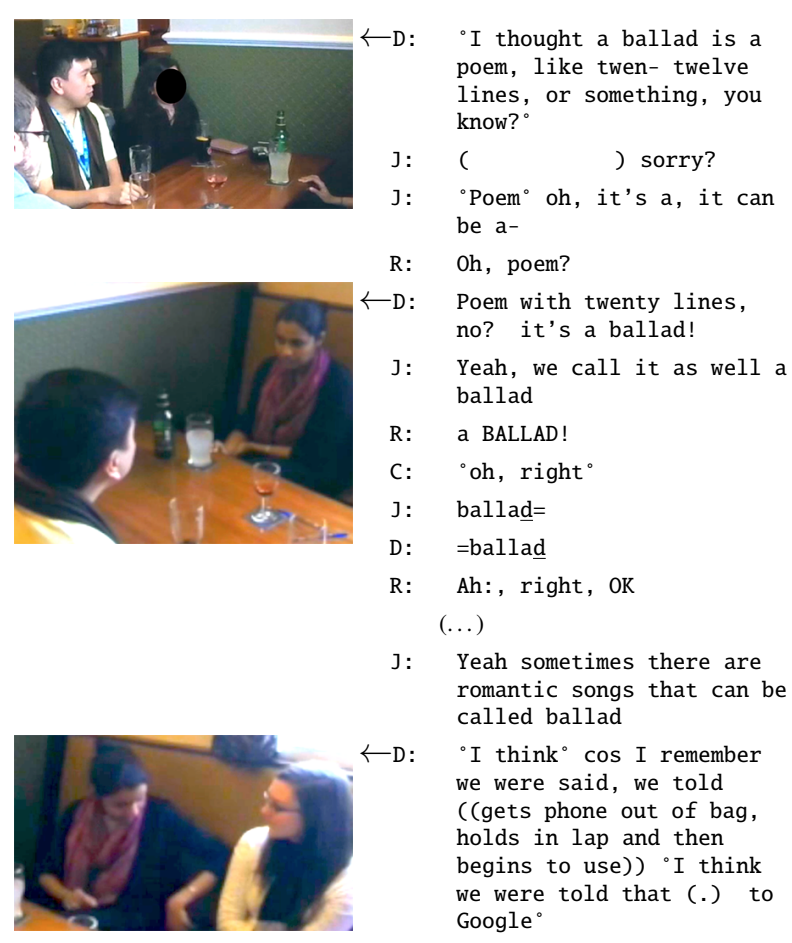

Fragment 1. Ballad Definition

This discussion, which lasts $34 \mathrm{~s}$ from the first utterance to the completion of the last remark, quickly leads to the introduction of a mobile phone to resolve the group dilemma. In fact, from the first definition of a ballad, as proposed by Dayna (who is also the member who begins to use her phone), it takes just $27 \mathrm{~s}$ for her to begin the process of retrieving her phone from her handbag. In the episode, we also note that Dayna, who in the informal interview later confessed to using her mobile phone "all the time", retrieves her phone from her handbag, and as she does so, continues to clarify her confusion over the exact 
definition of ballad. Then, just prior to the commencement of her mobile device use, she provides the confirmation to the group of the task she is about to perform by articulating her intention with " to Google". This declaration confirms that the purpose of her retrieving the device is that of resolving the group dilemma.

We also see further examples of this as, following this fragment, Dayna uses her phone within her lap, below that of the table edge; while using her mobile device she ostensibly disengages from the conversation through which the use was occasioned in the first place. The conversation amongst the friends quickly reverts to a previous topic that was taking place before this particular tangent occurred. Dayna remains disengaged from the conversation for a short time while she continues to use her phone.

There are various points within the sequence that, when combined, contribute to the occasioning of the mobile device. When Dayna utters "I think?" we can see signs of selfdoubt which is then followed by further conflicting definitions from others members. This helps to establish a 'state of confusion' within the group which is then followed by Dayna's act to retrieve her phone and make the statement " to Google ${ }^{\circ}$ ". By declaring her intent in this way, Dayna justifies her device use by making it accountable to the situation at hand. Dayna's actions are accountable to the members as they offer a way of dealing with the confusion, which in turn has contributed to the occasioning of the mobile device use. Similar situations in which mobile devices were used to retrieve information using search engines, and resolve conflicts within conversations, occurred in all the groups that took part in the study.

\section{Turn Allocation}

We now consider the relevance of this work in relation to the systematics of turn-taking allocation techniques, as given by Sacks et al. [49]. Accordingly, turn allocation works as either (1) an individual chooses to take the next turn in the conversation, or (2) the current speaker selects who will take the next turn within the conversation.

These two possible techniques are both observable within situations where mobile devices are occasioned in and through the conversation. For example, in the previous episode, we note that it was Dayna who self-selected using her phone. Equally, however, it is possible for a member to allocate device use to another member. Here, we present an episode taken from a later stage of the conversation of the same group. Fragment 2, which includes a small segment of a larger conversation around dog breeds, is between two of the group's members: Cally and Dayna. In this episode, we witness Cally attempt to describe the size of the breed of dog by gesturing with her hands, however, she then follows up this by instructing Dayna to use phone to look up more information.

This episode presents a straightforward example of mobile device use occasioning in and through the conversation, in which the speaker allocates the device use to another member. Dayna, who in the conversation had previously stated that she likes big dogs, enquires about the size of Cally's favourite dog breed (which we learn is the Miniature Schnauzer). Cally

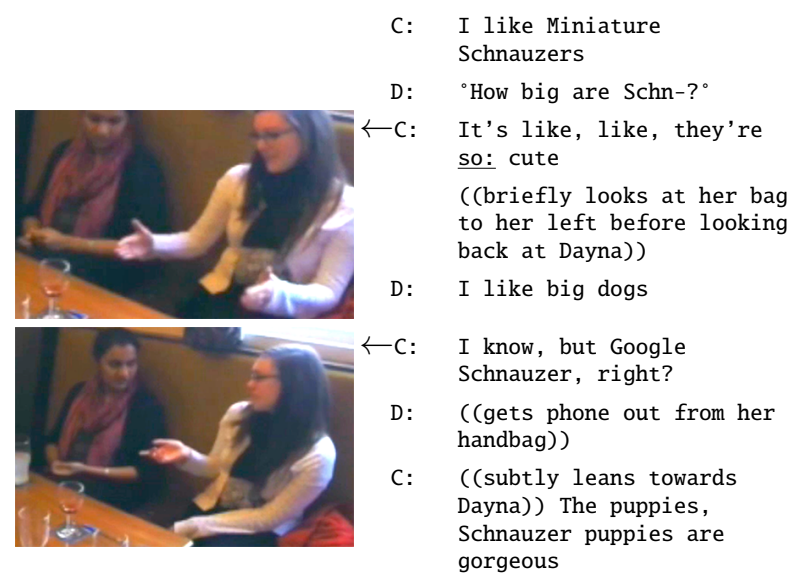

Fragment 2. Miniature Schnauzers

seems to glance around at her bag before turning back to face Dayna and then acknowledging Dayna's remark about big dogs before directly instructing her to "Google Schnauzer, right?". In review, this conversation both demonstrates the occasioning of the mobile device usage for purposes to research information, and that turn allocation of mobile device use is not restricted to self-selection. While Dayna was willing to use her phone, Cally identified herself as someone who uses her phone less often than Dayna, potentially contributing to the factor of allocating the device use to Dayna.

\section{Occasioning Ostensibly Unrelated to the Conversation}

Members can choose to engage with their mobile device for a variety of factors external to the conversation. For example, device use may be prompted by a device notification, or the individual can choose to use the mobile device at will. During the observations, we identified 14 instances in which we could observe notifications and subsequent device use during the study, which equates to $51 \%$ of all non-conversation related occasioning. We have excluded episodes from our analysis in which device use is neither accounted for, nor topicalised in some way in the conversation.

Fragment 3 presents an example in which occasioning that is apparently unrelated to the conversation is followed by topicalisation related to mobile device use in the conversation. In this episode, the owner of the mobile device, Lawrence, is using his mobile phone while a conversation is ongoing. Lawrence has recently rejoined the group after leaving for some time, with his phone left at the table. Upon his return to the table, he picks up his phone and begins to use it. He then brings up an email he has recently received, but he does this by interrupting an existing conversation around Christmas meals. In total, this episode includes four friends: Lawrence, Malcolm, Zöe, Jayne, and researcher Philip. We join the group $14 \mathrm{~s}$ after Lawrence returned to the table.

In order to identify the method of occasioning within this episode, we must consider that although Lawrence has almost continually used his mobile phone since returning to the table, this has ostensibly not been occasioned in and through the 

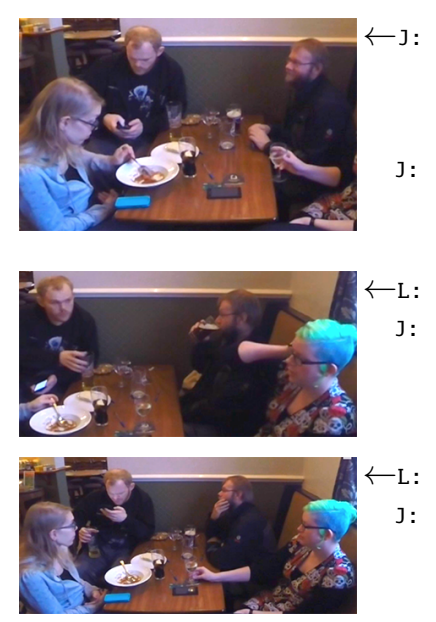

$<$ No, no, no $>$ I'm just saying mulled wine is not just Christmas

(...)

I think we went in, like, quite late, I tweeted, I took a photo and I tweeted No: $\uparrow$ cos it's-

What?

Beginning of September they had their, all their Christmas stuff out, and I was ${ }^{\circ}$ like oh my god, nobody (

'Jesus! ${ }^{\circ}$

We just booked ours (1.0) we do, me, and Liam, and James and Malcolm do (one every year and we) just booked it

M: Duboit $\uparrow$

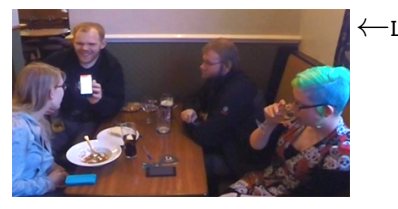

=Sorry, have you, um, Jonathan has sent round an email. This is great for your study isn't it? ((chuckles)) Have you seen the font size? (...)

M: Is that him or is that your phone fitting the line in?

Fragment 3. Email Interruption

conversation. He briefly takes a hiatus from using his mobile phone to have a drink and perhaps to clarify what the topic of the current conversation is: "What?", looking at Jayne as he does so. However, despite this brief interjection, Lawrence then turns back to using his mobile phone whilst the conversation runs its course, without looking at Jayne as she concluded her explanation. In turning back to his phone, he also lifts the device closer to his face, as can be seen within the imagery in the fragment. This posture suggests to those present that he is engrossed in studying the contents of his device's screen, which may be seen to display considerable involvement in his mobile device usage.

Lawrence's displayed orientation to the device is crucial to accounting for the later topicalisation of the contents of his screen in the conversation. Lawrence interrupts the current conversation, first with an apology for doing so ("Sorry"). $\mathrm{He}$ then makes his previous actions of holding his phone close to his face accountable by explaining that the email he received appears in a small size on his mobile phone. He also further corroborates this explanation by performing a screen-sharing gesture allowing others to see the email on his screen, providing further evidence for both his previous actions and his articulation, as exemplified when we see him share his phone with others at the end of Fragment 3.

Finally, this episode also demonstrates how some 'modes' of use, such as 'close to face' are remarkable, and therefore call for an explicit account to be offered to the co-participants. The member's display of holding his mobile device close to his face is accounted for in retrospect by introducing it to the group.
This practice of accounting for the use took place through interrupting the ongoing group conversation and bringing up the device use-related issue (small font size) that occasioned his holding of the device in a not naturally accountable way and thus, both a verbal and visual ('showing-and-telling') account was offered.

\section{Sustaining}

Members routinely engage in the activity of sustaining their co-presence within a social setting while interacting with a mobile device. Given the nature of the gathering, individuals may try to maintain a level of interaction with others in the collocated group, however, the form this interaction takes varies given that the individual must also balance their focus with their mobile device and the demands it places on their attentional orientation.

We identified two primary foci that this sustaining activity can take: managing one's relation to and within the social situation, and managing the mobile device's role within the situation. The social norms that govern acceptable behaviour for a current setting (i.e. the pub) provide the framework for members to manage both of these relationships [53]. Our analysis identified two methods through which members sustained their mobile device use and co-presence within the collocated group: the first, demonstrating continual social interaction, is where members work to maintain a presence (to a varying degree) within the conversation; and the second, performing accountable actions, is where members make their device interaction both observable and reportable to the other members within the setting.

\section{Demonstrating Continual Social Interaction}

The first method we observed adopted by individuals to sustain their device interactions is to account for the usage while also performing actions that provide a contribution to the social setting. We briefly present the episode in Fragment 4 that includes a conversation between Jayne and Zöe, as Zöe is looking for a photo on Facebook on her mobile phone. In this episode, we see Jayne talking to Zöe about the photo during this task, with Zöe's gaze remaining fixed on her phone.

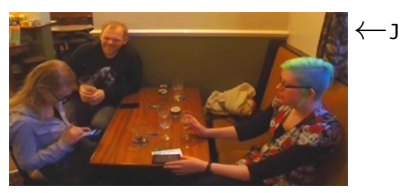

There's an amazing <well, no, no, no> there's an amazing photo of dunno if you've got it actually of of erm (tt) (Q.5) Malcolm with Richard (2.1)

J: You know Richard from my year?

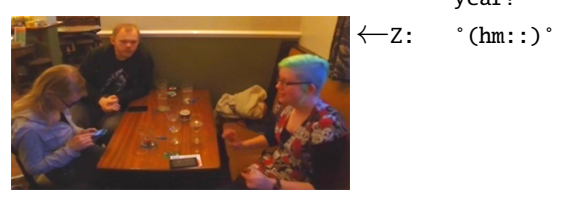

Fragment 4. Verbal Nudge

During this episode, which only lasts a few seconds, we see that as Jayne provides her comment, she looks towards Zöe, but does not receive a response. She follows this up with a question: "You know Richard from my year?", to which she 
receives a subtle and succinct acknowledgement of her comment (" $\left.{ }^{\circ}(\mathrm{hm}: \mathrm{:})^{\circ}{ }^{\circ}\right)$. This response is typical of a perfunctory response members give when they are preoccupied with something else. As Zöe provides her response, she maintains her posture of keeping her head down and her gaze fixed on her mobile phone. However, Zöe's response may be seen to indicate that she is still listening. This episode is an example of work to maintain presence within conversation, even at a minimal level, while also continuing to use a mobile device.

\section{Accounting for Device Use}

We also observed that individuals made use of interactional resources, such as body orientation, gaze, and talk to highlight their device interactions by making it observable-andreportable to those within the setting. One common observed approach is to continually articulate one's actions to the group, thereby offering a verbal account for the device use, be it in a specific detail such as verbalising what you are typing, or an abstract definition of the task you are attempting. We demonstrate the way in which individuals account for their actions by joining Lawrence, Jayne, Zöe and Malcolm again. In the episode, given in Fragment 5, the group are discussing shorthand notation. Lawrence has expressed an interest in learning shorthand notation, and Jayne explains that she had previously been taught one form of notation although also discusses another form of which she is aware.

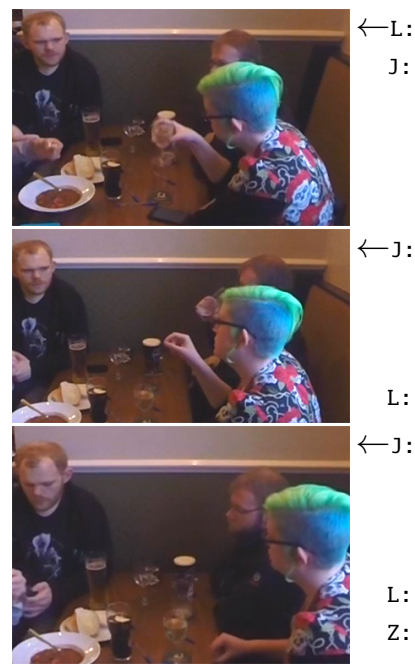

Isn't it mainly phonetic? It's like:

(3.2)

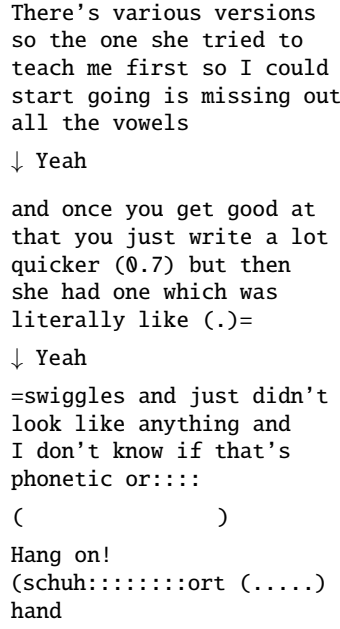
so the one she tried to teach me first so I could start going is missing out all the vowels

$\downarrow$ Yeah

and once you get good at that you just write a lot quicker ( 0.7$)$ but then she had one which was literally like (.)=

$\downarrow$ Yeah

=swiggles and just didn't look like anything and I don't know if that's phonetic or: : :

)

Hang on!

(schuh::::::::ort $(\ldots \ldots)$ hand

M: $\quad($

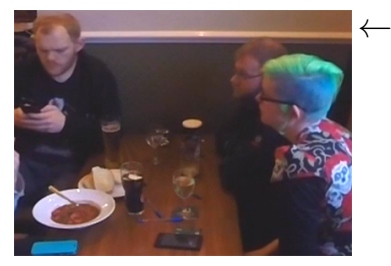

Fragment 5. Shorthand

This episode presents both methods of sustainment: we see Lawrence demonstrate his continual social presence when he responds to Jayne's explanation of the first shorthand notation that she learnt with his remark “ $\downarrow$ Yeah", and later we see the provision of an account in which Lawrence begins to spell out the word shorthand while typing on his phone. Although he does not provide visual confirmation to the other members, or indeed, specific explanation of what his exact interaction is with his device, the clear implication of his spelling out the phonetic sounds is that he is presently typing the word into a search engine. Our later conversation confirmed that he was using Google to find information about shorthand. Unfortunately, while Lawrence demonstrates that he is maintaining awareness of the verbal aspects of the conversation, he fails to respond to gestures used by Jayne to exemplify her explanations. Jayne makes two visual contributions to the interaction, first demonstrating the form of shorthand in the air (as seen in the second image in the Fragment) and then on the table as she explains the second form of shorthand.

In addition to articulating actions, the process of providing a continual account of actions can include more visual aspects such as making the device screen visible (i.e. available for glancing). This could be to allow others to engage as a spectator during your device usage, or alternatively to engage in a collaborative task that allows one-or-more other members within the setting to contribute. We saw both of these behaviours as members were searching for information to contribute, or to corroborate members' opinions.

\section{Disengaging}

The disengaging of mobile devices can itself be brought about by a number of different factors pertaining to the conversation and the mobile device use (e.g. search task completion). External factors that are not related to the conversation or the mobile device may play a part in this disengaging, although we have not examined these in our research. Additionally, a process of 're-entering the conversation' may follow disengaging from a mobile device. Disengagement from mobile device usage concludes sustaining 'concurrent' device interaction and conversation (as outlined in the previous section). We further observed that the disengagement of mobile devices can also either be temporary or semi-permanent in nature. We define temporary disengagement to be where a task is still ongoing, but the user halts their mobile device interactions, and semipermanence to be the completion, or failure to complete, a particular task. We use the term semi-permanence in the latter case as an individual may later use their phone for some other cause, irrespective to the outcome of the previous interaction.

\section{Disengaging In and Through Conversation}

We have already presented a number of episodes in which mobile device use is occasioned in and through the conversation, both in terms of resolving debates, or enhancing one's explanation or viewpoint. When looking at disengagement, relevant situational features include the interaction before and after the disengagement occurs, including how the member 'rejoins' the conversation. Mobile devices place a demand on an individual's attentional resources, and shifting focus from one task to another is likely to be problematic. For example, from the temporary disengagement highlighted in Fragment 3, when Lawrence asks "What?" he articulates that he was unable to maintain a full awareness of the conversation while using his mobile phone. 
We present one example of disengaging from mobile device use through the evolution of conversation, focusing on the point at which the member suspends their mobile device usage to orientate their focus back to the conversation. In this episode, given in Fragment 6, we join a third group of friends: Leonard, Christine, Janice, and the researcher Philip. The participants have only recently arrived for the study, and although they have been through the process of informed consent, the researcher uses this opportunity to recap the information that was given to participants in the initial email that was used to promote the study. Before we join the group, Leonard caught a glimpse of Philip's mobile phone, and clarifies the specific model of phone he owns. As we join the group, Leonard, who is holding his phone, moves to hold it next to Philip's phone as a visual comparison.

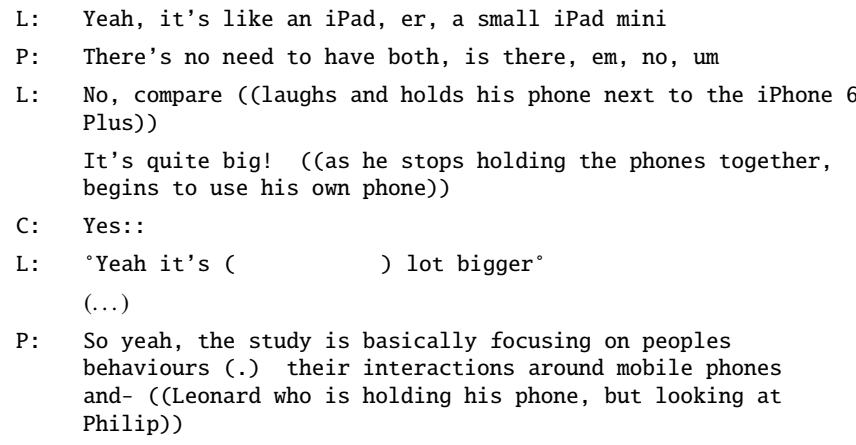

Fragment 6. Distraction

The change in conversation topic by Philip leads to Leonard sitting back in his chair and temporarily halting his mobile device usage. As Philip starts talking, we observe Leonard place his (unlocked) phone down on the table, face up, and look towards Philip. This may be seen to display an acknowledgement of the importance of the social (research) setting within which he finds himself. However, it is noteworthy to highlight that the action of leaving the mobile device unlocked may declare his intention to resume usage later, and perhaps it points to the untimely nature of the topic change that interrupted the task he was attempting to complete.

Disengaging from the Device as a Result of Task Completion Finally, we rejoin Cally and Dayna from the episode in Fragment 2 as one example where the purpose for which the device usage was occasioned has been satisfied. In the previous episode, Dayna used her phone to provide an enhancement to Cally's explanation of her favourite dog breed. The continuation of the episode, given in Fragment 7, takes place roughly $11 \mathrm{~s}$ after we left the action. In the time we have been away from the action, Cally had briefly engaged with the main conversation before returning to help co-ordinate the search task with Dayna.

Instead of simply leaving Dayna to complete the task alone, we see the mobile device become an artefact embedded within the conversation between the pair, and a collaborative search task forms. Using terminology by Brown et al. [3], we could describe Dayna as "driving" the search task with Cally as a "passenger", or back-seat driver, providing support to Dayna throughout. We can see that both members continually take turns to engage with each other, while Dayna acts as the operator of the mobile device as the pair work together to complete the task. This episode contains a number of notable observations that corroborate findings in collaborative search literature, as we observe Dayna re-orienting the mobile display towards Cally, and Cally re-positions herself to engage with the mobile search task [3]. We note that this task, which is co-steered by both members, is cut short and the episode ends with an articulated apology by Dayna: "My internet is rubbish so this may take some time ${ }^{\circ}$. In this utterance, Dayna removes her mobile device from the conversation, in which it had become embedded, because of the slowness of her mobile Internet. Although technological progress continually improves the responsiveness of user interfaces and device connectivity, issues still persist in situations where a mobile device is interleaved with a conversation. This may be due to the pace of talkconversations can quickly move on, especially when more than two individuals are co-present and engaged.

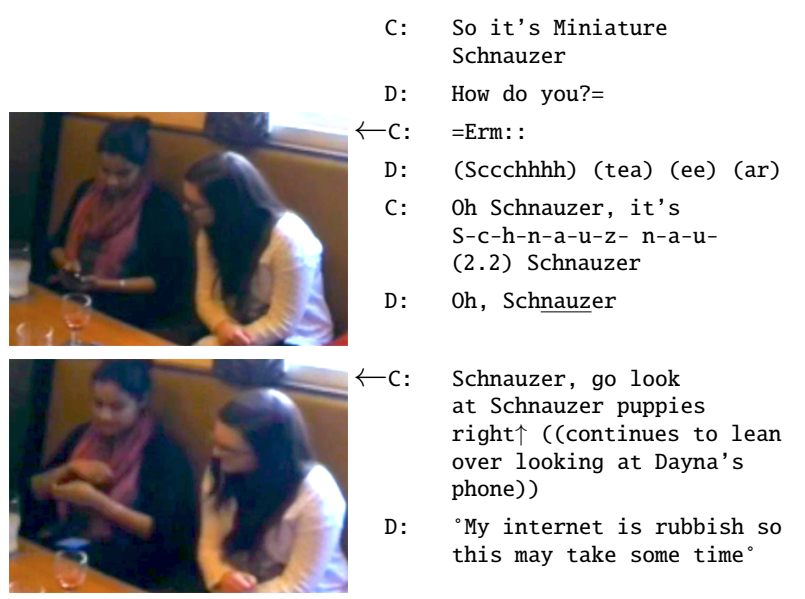

Fragment 7. Collaborative Search

Following this episode, Dayna leaves her phone unlocked in her lap, although a short while after the device automatically locks itself. Later on, Dayna unlocks her phone and, following confirmation of the result from Cally, shares the photo with others in the whole group. She then locks the mobile phone and puts it back on her lap, given the task of identifying the dog breed, and reinforcing Cally's opinion, has been completed. The entire process from Cally's initial instruction to the demonstration to the group took $3 \mathrm{~m} \mathrm{14s}$, although possibly could have been performed quicker had the mobile device not been temporarily removed from the conversation.

To recap, in our analysis we found two methods through which mobile device usage was disengaged from and we have presented two exhibits that demonstrate these interactional methods. These also highlight the importance of considering how disengagement occurs, and the interactional trouble that may follow afterwards. 


\section{INTERLEAVING USE WITH SOCIAL INTERACTION}

Thus far, we have provided exhibits that demonstrate the methods through which members employ interactional resources to accomplish the interleaving work of using mobile devices in conversation. We now unpack these findings in order to reveal the machinery of interaction [48] that underlies the interleaving work. It is at this point at which we transfer, as Sacks put it, "our view of 'what happened', from a matter of particular interaction done by particular people, to a matter of interactions as products of a machinery" [48, p. 26]. We highlight the methods that comprise the machinery below.

\section{The Machinery of Interaction}

In occasioning device use, members exhibited two fundamental methods: occasioning in and through conversation, and occasioning ostensibly unrelated to conversation. With the former, we witnessed mobile device use both as a tool to answer questions and resolve disagreements within the group, and as a utility to help reinforce or corroborate a member's point. Furthermore, where the occasioning warranted sustained usage, mobile device use became embedded in a number of situations within the setting: for example, the mobile device interactions around providing information to the group on Cally's favourite dog breed led to a collaborative search task. In reviewing exhibits of the latter of the two occasioning methods, we highlighted that unrelated mobile device use itself is accountable to the group, which may be done verbally and/or visually by bringing up the mobile use-related topic in the conversation. As with the former occasioning method, this form of occasioning succinctly leads to the management of a mobile device allowing for the conversation to re-orient to and sustain the usage. In both of these situations, the management of the mobile device was dependant on that of the method through which the usage became occasioned.

Sustaining mobile device use whilst the conversation continues is done in and through members performing actions to continue to display their attention to the conversation in line with the social norms of the setting and purpose of the gathering. We saw that members visually shared their devices with others, be it either by making the device use visible, or by embedding the device use in the conversation (e.g. Fragments 3 and 7 respectively). We also saw where individuals made their actions audibly accountable; to demonstrate to the group that, despite the completion of a task, there is an emphasis on remaining engaged with the conversation (e.g. Fragment 5). Equally, we observed a number of ways members demonstrate attentiveness to the conversation while using a mobile device, for example as in Fragment 4.

Disengaging from mobile devices could also occur through a number of different methods, disengaging in and through interaction on the one hand, or by satisfying the purpose of mobile phone use on the other: for example, if the mobile device was occasioned for a particular purpose, then once the purpose of its usage has been met, the need for the mobile device may be lost and usage is halted. The way in which disengagement is achieved depends on how the mobile device use was occasioned and sustained, as well as the present social situation. Furthermore, mobile device disengagement may only be temporary, as we witnessed in a number of cases, if the actual operation of completing has not been brought to a close. For example, in some cases, the task was ongoing but would take some more time, or in other cases, members would re-orientate their focus of attention to the conversation. In the cases we presented, this could be considered temporary disengagement in and through the conversation.

\section{The Problematic Nature of Interleaving}

While we wish not to be misunderstood to make moral judgements such as whether device use in social settings is socially acceptable, we do want to critically examine the interleaving practices we observed in terms of interactional trouble it causes for the co-participants. We have seen that interleaving device use with social interaction places continual demands on the member to remain engaged, or at least display attentiveness to the conversation while using their device (e.g. Fragment 4). However, we have seen evidence that suggests it may in fact be difficult to pay attention to a conversation whilst using the device (e.g. Fragments 4 and 5). This is further corroborated by literature on divided attention, with performance factors including task difficulty and practice [38, p. 38]. For example, individuals may find it difficult to read and understand information on webpages while also engaging with a conversation.

Although we would not disagree with characterising the interleaving practices demonstrated in episodes in which members co-orient to one member's mobile device use in and through the conversation (e.g. Fragments 2 and 3 ) as successful, this co-orientation does not come without interactional trouble. In Fragment 3 the device user interrupts the conversation in topicalising his screen contents, and later in Fragment 7 the co-oriented device use is disengaged from with an apology "My internet is rubbish" — and the purpose for which the device use was instigated in the first place (looking up a dog breed) remains (temporarily) unsatisfied.

In summary, while the trouble we observed was subtle, and in all cases repaired swiftly in and through interaction, it may nevertheless be fair to say that interleaving practices are interactionally problematic. Interleaving practices frequently feature interruptions, recapitulations of the conversation for members re-joining, displays of attentiveness despite ostensible inattentiveness, and prompts of absent-minded members. We also saw how individuals apologised for their device use, or the slowness of their device, and for bringing device userelated topics into the conversation. The interactional problems revealed in our data suggest current mobile device use is perhaps ill-suited to be interleaved with social interaction in unproblematic ways. In our view, this calls for a program of work that investigates how interleaving practices may best be supported by design.

\section{DISCUSSION}

We have presented the findings from our fieldwork in a casual social setting, and made use of fragments to explicate the interactional methods through which the work of interleaving mobile device use and conversation is accomplished. Whilst it is a well-known challenge in the CSCW community to design 
systems that support collaborative interactions within collocated groups, we felt that there was a need to go and look to understand in detail the interactional work that members undertake to interleave mobile device use while engaged in collocated interactions. Our work focused on documenting the accountable methods that members performed in occasioning, sustaining, and disengaging from device use. A number of related pieces from the academic literature have looked at coherent user experiences in collocated groups (e.g. [9, 34]). We also felt compelled by the rhetoric around 'social isolation' and other negative connotations of device use in social settings [55]. Our findings forbid such simplifications, instead, they show the ways in which interleaving practices are situationally context-shaped and context-shaping [21], and interactionally problematic, as evidenced through features such as apologies, interruptions, and inattentiveness.

\section{Embedding Mobile Devices in Conversation}

In our analysis, we saw that mobile devices are occasioned and become embedded in conversations for several purposes, one of which was information seeking, as highlighted by similar literature $[3,6]$. Information seeking-related mobile device use was occasioned in and through the conversation, for example to clarify points or to resolve disagreements. Information seeking in collocated settings is arguably a practice enabled by smartphones; a practice that could in future be provided or enhanced by the introduction of differing technologies, such as wearable mobile devices and interactive tables $[13,36]$. Although we did not examine how people felt about the use of mobile devices in detail, others have discussed the loss of "authentic banter" due to the introduction of mobile phones into conversations [53], however, we have in fact witnessed humour arising from topics actually instigated as a result of mobile device use.

We further found that members often took great care to articulate their actions when devices are embedded to sustain their usage and social presence, be it through utterances while their gaze was fixed on their device, or an announced statement of intent. We note the use of interactional resources and social cues by members in the setting allowed them to purvey their current focus and task. In one such example we included, body co-orientation accountably displayed participants working together (see Fragment 2) [50]. Furthermore, member's orientation towards their mobile device screen whilst visibly typing messages for itself provides a non-verbal, yet observable-and-reportable account of their actions.

In addition, our study also echoes the literature on interruptions that has found an impact on our attentional orientation [15, 25]. We saw several instances in which members responded to notifications; such a 'readiness to respond' may perhaps be related to the informal nature of the setting in which we conducted our fieldwork [31]. Authors have suggested that although there is a need to be accountable towards collocated members, there is equally a duty to manage accountabilities to those we are remotely connected to [54]. This may have helped to develop a contentious situation where individuals feel that they need to constantly respond to the virtual interruptions that permeate their physical surroundings [1].

\section{The Role of Mobile Devices in Interactional Trouble}

While work has been done to support mobile device interactions in collaborative tasks, there still remains an issue with the speed (e.g. 'sluggishness') of device use that makes aligning it with the social interaction challenging: conversations ebb and flow, they may get faster and slower, whereas device interactions do not. Sluggish device responsiveness and inflexible alignment to conversational pace makes it extremely difficult for device use to remain in step with the conversation. It arguably increases the potential to disrupt the conversation. For example, our work also shows that mobile device use was eventually given up on because of the lack of responsiveness (during internet search), opening up design challenges around speed and alignment that need to be addressed in order for devices to enable unproblematic interleaving in conversations.

We feel that such interactional troubles are unlikely to be solved with one 'solution', just as there is not a single definable 'problem', but many smaller, nuanced issues with mobile device interactions in conversation. As devices increase in processing power and sensory input, and the ability to offload functionality to the 'cloud' increases, it is likely that a number of these issues that contribute to interactional troubles will be solved in the near-term. In terms of disruptions, while manufacturers have implemented simple controls to mute device notifications, such actions are not (yet) automated or linked to sensory data. We may ask the same questions that others have asked of the impact of mobile devices in conversations, for example, whether it is detrimental to conversations [3]. We note that the literature has highlighted the potential of mobile devices to be utilised to avoid social interaction [27, 52]. This may also contribute to negative reflections on mobile devices in social settings, which have been highlighted in literature as being a symptom of "double-standards", where members were critical of device users' actions, but also engaged in those same actions themselves [1]. Furthermore, while some say that individuals use mobile devices to avoid awkward situations, describing the phenonem as social isolation [55], it has also been noted that many with anxiety disorders or who are shy may shield themselves from unmanageable situations [57].

\section{Ideas for Future Work}

Finally, we offer considerations on a number of different avenues future design work may take. For example, work could follow the response of supporting the observed practices through design by making mobile devices less invasive and demanding of an individual's attentional resources. This work could turn upon utopian ideas inspired by calm computing or context awareness, and could be attempted by using technologies such as 'smart tables', context sensing applications on mobiles, making mobile notifications sensitive to some current group context [16], or the use of additional screens in collocated interaction to facilitate collaborative tasks [34]. Alternative ideas could be around building a 'provocative' smart phone that prevents users from opening certain apps on mobile phones when the device detects ongoing conversation; not to 'solve' a problem, but to evoke critical reflection by the members of the setting [46, p. 137]. Regardless of the approach, we would suggest to frame design interventions as 
an attempt to create a resource members draw upon in everyday social interactions (cf. [23]). Perhaps most importantly, researchers may then go and look at real-world deployments to study how members actually mesh the intervention with the broader assembly of resources drawn upon in interaction.

\section{CONCLUSION}

In this paper we presented the findings from our ethnographic study to identify the interactional methods through which members co-ordinate the work of interleaving mobile device use with conversation in a pub setting. We presented exhibits that demonstrate the methods through which device use is occasioned, sustained, and disengaged from conversations, unpacked the machinery of interaction that underlies these methods, and revealed the ways in which they are interactionally problematic as evidenced in apologies, interruptions, and inattentiveness. We conclude that there is value in research on collaborative collocated work, but that taking our findings seriously means there is a need for future work to explore the ways in which interleaving practices may be supported, or disrupted, by design.

\section{ACKNOWLEDGEMENTS}

We would like to thank: The Johnson Arms, Nottingham, for graciously providing the venue for our observations; the anonymous reviewers for their constructive feedback; and our colleagues for their contributions throughout the project. The authors are supported by the Horizon Centre for Doctoral Training at the University of Nottingham (RCUK Grant No. EP/G037574/1), by the RCUK's Horizon Digital Economy Research Institute (RCUK Grant No. EP/G065802/1), and by grants EP/L02392X/1, and EP/M000877/1. The data that this paper is based on is provided in this paper.

\section{REFERENCES}

1. Morgan G. Ames. 2013. Managing Mobile Multitasking: The Culture of iPhones on Stanford Campus. In Proceedings of the 2013 Conference on Computer Supported Cooperative Work (CSCW'13). ACM, New York, NY, USA, 1487-1498. DOI :

http://dx. doi . org/10.1145/2441776.2441945

2. Joanna Bergstrom-Lehtovirta, Tommy Eklund, Antti Jylhä, Kai Kuikkaniemi, Chao An, and Giulio Jacucci. 2013. BubblesDial: Exploring Large Display Content Graphs on Small Devices. In Proceedings of the 12th International Conference on Mobile and Ubiquitous Multimedia (MUM'13). ACM, New York, NY, USA, Article 1. DOI : http://dx.doi .org/10.1145/2541831.2541845

3. Barry Brown, Moira McGregor, and Donald McMillan. 2015. Searchable Objects: Search in Everyday Conversation. In Proceedings of the 18th ACM Conference on Computer Supported Cooperative Work \& Social Computing (CSCW'15). ACM, New York, NY, USA, 508-517. DOI : http: //dx . doi . org/10.1145/2675133.2675206

4. Michael Bull. 2005. No Dead Air! The iPod and the Culture of Mobile Listening. Leisure Studies 24, 4 (Jan. 2005), 343-355. DOI :

http://dx. doi . org/10.1080/0261436052000330447
5. Scott W. Campbell and Yong Jin Park. 2008. Social Implications of Mobile Telephony: The Rise of Personal Communication Society. Sociology Compass 2, 2 (March 2008), 371-387. DOI :

http: //dx. doi . org/10.1111/j. 1751-9020.2007.00080.x

6. Karen Church, Antony Cousin, and Nuria Oliver. 2012. I Wanted to Settle a Bet!: Understanding Why and How People Use Mobile Search in Social Settings. In Proceedings of the 14th International Conference on Human Computer Interaction with Mobile Devices and Services (MobileHCI '12). ACM, New York, NY, USA, 393-402. DOI :

http://dx. doi . org/10.1145/2371574.2371635

7. Ian Clarke, Ian Kell, Ruth Schmidt, and Claudio Vignali. 2000. Thinking the thoughts they do: Symbolism and meaning in the consumer experience of the "British pub". British Food Journal 102, 9 (Oct. 2000), 692-710. DOI : http://dx. doi .org/10.1108/00070700010362059

8. Helen Cole and Danaë Stanton. 2003. Designing mobile technologies to support co-present collaboration. Personal and Ubiquitous Computing 7, 6 (Dec. 2003), 365-371. DOI:

http: //dx. doi . org/10.1007/s00779-003-0249-4

9. Scott Counts and Eric Fellheimer. 2004. Supporting Social Presence Through Lightweight Photo Sharing On and Off the Desktop. In Proceedings of the SIGCHI Conference on Human Factors in Computing Systems (CHI '04). ACM, ACM, New York, NY, USA, 599-606. DOI: http://dx.doi . org/10.1145/985692.985768

10. Andrew Crabtree, Mark Rouncefield, and Peter Tolmie. 2012. Doing Design Ethnography. Springer, London. DOI : http: //dx . doi . org/10 . 1007/978-1-4471-2726-0

11. Edward B. Cutrell, Mary Czerwinski, and Eric Horvitz. 2000. Effects of Instant Messaging Interruptions on Computing Tasks. In CHI 'OO Extended Abstracts on Human Factors in Computing Systems (CHI EA 'O0). ACM, New York, NY, USA, 99-100. DOI: http: //dx. doi . org/10.1145/633292.633351

12. Abigail Durrant, Duncan Rowland, David S. Kirk, Steve Benford, Joel E. Fischer, and Derek McAuley. 2011. Automics: Souvenir Generating Photoware for Theme Parks. In Proceedings of the SIGCHI Conference on Human Factors in Computing Systems (CHI'11). ACM, New York, NY, USA, 1767-1776. DOI : http: //dx . doi . org/10.1145/1978942.1979199

13. Wim Fikkert, Michiel Hakvoort, Paul van der Vet, and Anton Nijholt. 2009. Experiences with Interactive Multi-touch Tables. In Intelligent Technologies for Interactive Entertainment, Anton Nijholt, Dennis Reidsma, and Hendri Hondorp (Eds.). Lecture Notes of the Institute for Computer Sciences, Social Informatics and Telecommunications Engineering, Vol. 9. Springer Berlin Heidelberg, 193-200. DOI :

http://dx. doi .org/10.1007/978-3-642-02315-6_19 
14. Joel E. Fischer. 2010. Interrupting the Here and Now: Implications and Opportunities. In Mensch \& Computer 2010: Interaktive Kulturen, Jürgen Ziegler and Albrecht Schmidt (Eds.). Oldenbourg Verlag, München, 159-168.

15. Joel E. Fischer, Chris Greenhalgh, and Steve Benford. 2011. Investigating Episodes of Mobile Phone Activity as Indicators of Opportune Moments to Deliver Notifications. In Proceedings of the 13th International Conference on Human Computer Interaction with Mobile Devices and Services (MobileHCI'11). ACM, New York, NY, USA, 181-190. DOI :

http: //dx. doi . org/10.1145/2037373.2037402

16. Joel E. Fischer, Stuart Reeves, Stuart Moran, Chris Greenhalgh, Steve Benford, and Stefan Rennick-Egglestone. 2013. Understanding Mobile Notification Management in Collocated Groups. In Proceedings of the 13th European Conference on Computer Supported Cooperative Work (ECSCW'13). Springer, London, 21-44. DOI : http://dx.doi . org/10 . 1007/978-1-4471-5346-7_2

17. Joel E. Fischer, Nick Yee, Victoria Bellotti, Nathan Good, Steve Benford, and Chris Greenhalgh. 2010. Effects of Content and Time of Delivery on Receptivity to Mobile Interruptions. In Proceedings of the 12th International Conference on Human Computer Interaction with Mobile Devices and Services (MobileHCI '10) (MobileHCI'10). ACM, New York, NY, USA, 103-10. DOI : http://dx. doi . org/10.1145/1851600.1851620

18. Kate Fox. 2004. Watching the English: The Hidden Rules of English Behaviour. Hodden \& Stoughton, London.

19. Hans Geser. 2006. Is the Cell Phone Undermining the Social Order?: Understanding Mobile Technology from a Sociological Perspective. Knowledge, Technology \& Policy 19, 1 (2006), 8-18. DOI : http: //dx . doi . org/10.1007/s12130-006-1010-x

20. Erving Goffman. 1963. Behavior in Public Places. Simon and Schuster, New York.

21. Charles Goodwin and John Heritage. 1990. Conversation Analysis. Annual Review of Anthropology 19, 1 (Oct. 1990), 283-307. DOI : http: //dx . doi . org/10.1146/annurev . an . 19.100190.001435

22. Christian Heath, Jon Hindmarsh, and Paul Luff. 2010. Video in Qualitative Research. SAGE.

23. Jon Hindmarsh and Christian Heath. 2000. Sharing the Tools of the Trade The Interactional Constitution of Workplace Objects. Contemporary Ethnography 29, 5 (Oct. 2000), 523-562. DOI :

http://dx. doi .org/10.1177/089124100129023990

24. Jussi Holopainen, Andrés Lucero, Hannamari Saarenpää, Timo Nummenmaa, Abdallah El Ali, and Tero Jokela. 2011. Social and Privacy Aspects of a System for Collaborative Public Expression. In Proceedings of the 8th International Conference on Advances in Computer Entertainment Technology (ACE'11). ACM, New York, NY, USA, Article 23. DOI :

http://dx. doi . org/10.1145/2071423.2071452
25. James M. Hudson, Jim Christensen, Wendy A. Kellogg, and Thomas Erickson. 2002. "I'd Be Overwhelmed, But It's Just One More Thing To Do": Availability and Interruption in Research Management . In Proceedings of the SIGCHI Conference on Human Factors in Computing Systems (CHI '02). ACM, New York, NY, USA, 97-104. DOI: http://dx. doi .org/10.1145/503376.503394

26. Lee Humphreys. 2005. Cellphones in public: social interactions in a wireless era. New Media \& Society 7, 6 (Dec. 2005), 810-833. D0I :

http: //dx . doi . org/10.1177/1461444805058164

27. Lee Humphreys. 2010. Mobile social networks and urban public space. New Media \& Society 12, 5 (Aug. 2010), 763-778. DOI :

http: //dx. doi . org/10.1177/1461444809349578

28. Lee Humphreys, Thilo Von Pape, and Veronika Karnowski. 2013. Evolving Mobile Media: Uses and Conceptualizations of the Mobile Internet. Computer-Mediated Communication 18, 4 (May 2013), 491-507. DOI : http://dx. doi . org/10.1111/jcc4. 12019

29. Brigitte Jordan and Austin Henderson. 1995. Interaction Analysis: Foundations and Practice. the Learning Sciences 4, 1 (Jan. 1995), 39-103. D0I : http://dx.doi.org/10.1207/s15327809j1s0401_2

30. Oskar Juhlin and Elin Önnevall. 2013. On the Relation of Ordinary Gestures to TV Screens: General Lessons for the Design of Collaborative Interactive Techniques. In Proceedings of the SIGCHI Conference on Human Factors in Computing Systems (CHI '13). ACM, New York, NY, USA, 919-930. DOI : http: //dx. doi . org/10.1145/2470654.2466118

31. Claudia Krehl, Sarah Sharples, and Martin Flintham. 2013. Less is More: Classifying Mobile Interactions to Support Context Sensing in Journeys. In Proceedings of the 27th International BCS Human Computer Interaction Conference (BCS-HCI '13). BCS, Swinton, Article 8.

32. Eric Laurier, Angus Whyte, and Kathy Buckner. 2001. An ethnography of a neighbourhood café: informality, table arrangements and background noise. Mundane Behaviour 2, 2 (July 2001), 195-232.

33. Hugo Lopez-Tovar, Andreas Charalambous, and John Dowell. 2015. Managing Smartphone Interruptions through Adaptive Modes and Modulation of Notifications. In Proceedings of the 20th International Conference on Intelligent User Interfaces (IUI'15). ACM, New York, NY, USA, 296-299. DOI :

http: //dx. doi . org/10.1145/2678025.2701390

34. Andrés Lucero, Jussi Holopainen, and Tero Jokela. 2012. MobiComics: Collaborative Use of Mobile Phones and Large Displays for Public Expression. In Proceedings of the 14th International Conference on Human-Computer Interaction with Mobile Devices and Services (MobileHCI'12). ACM, New York, NY, USA, 383-392. DOI : http://dx. doi . org/10.1145/2371574.2371634 
35. Andrés Lucero, Matt Jones, Tero Jokela, and Simon Robinson. 2013. Mobile Collocated Interactions: Taking an Offline Break Together. interactions 20, 2 (March 2013), 26-32. DOI :

http://dx. doi .org/10.1145/2427076.2427083

36. Andrés Lucero and Akos Vetek. 2014. NotifEye: using interactive glasses to deal with notifications while walking in public. In Proceedings of the 11th Conference on Advances in Computer Entertainment Technology (ACE '14). ACM, New York, NY, USA, Article 17. DOI : http://dx. doi . org/10.1145/2663806.2663824

37. Paul Luff and Marina Jirotka. 1998. Interactional Resources for the Support of Collaborative Activities: Common Problems in the Design of Technologies to Support Groups and Communities. In Community Computing and Support Systems, Toru Ishida (Ed.). Springer, Berlin, Heidelberg, 249-266. DOI : http://dx.doi .org/10 . 1007/3-540-49247-X_17

38. Nick Lund. 2002. Attention and Pattern Recognition. Routledge.

39. Sus Lundgren, Joel E. Fischer, Stuart Reeves, and Olof Torgersson. 2015. Designing Mobile Experiences for Collocated Interaction. In Proceedings of the 18th ACM Conference on Computer Supported Cooperative Work \&\#38; Social Computing (CSCW'15). ACM, New York, NY, USA, 496-507. DOI :

http://dx. doi . org/10.1145/2675133.2675171

40. Sus Lundgren and Olof Torgersson. Bursting the Mobile Bubble. In Designing Mobile Face-to-Face Group Interactions workshop at ECSCW'13.

41. Kenton P. O'Hara, April Slayden Mitchell, and Alex Vorbau. 2007. Consuming Video on Mobile Devices. In Proceedings of the SIGCHI Conference on Human Factors in Computing Systems (CHI '07). ACM, New York, NY, USA, 857-866. DOI :

http://dx.doi .org/10.1145/1240624.1240754

42. Virpi Oksman and Jussi Turtiainen. 2004. Mobile Communication as a Social Stage: Meanings of Mobile Communication in Everyday Life among Teenagers in Finland. New Media \& Society 6, 3 (June 2004), 319-339. DOI : http://dx. doi .org/10.1177/1461444804042518

43. Ray Oldenburg. 1989. The Great Good Place. Paragon House, New York. DOI : http://dx. doi . org/10.1093/sf/69.3.931

44. Antti Oulasvirta, Tye Rattenbury, Lingyi Ma, and Eeva Raita. 2011. Habits make smartphone use more pervasive. Personal and Ubiquitous Computing 16, 1 (June 2011), 105-114. DOI :

http://dx.doi.org/10.1007/s00779-011-0412-2

45. Oscar Peters and Somaya ben Allouch. 2005. Always connected: a longitudinal field study of mobile communication. Telematics and Informatics 22, 3 (Aug. 2005), 239-256. DOI :

http://dx.doi .org/10.1016/j . tele. 2004 . 11.002
46. Johan Redström. 2006. Towards user design? On the shift from object to user as the subject of design. Design Studies 27, 2 (2006), 123-139. D0I :

http: //dx. doi .org/10.1016/j . destud. 2005.06.001

47. John Rooksby, TimothyE. Smith, Alistair Morrison, Mattias Rost, and Matthew Chalmers. 2015. Configuring Attention in the Multiscreen Living Room. In Proceedings of the 14th European Conference on Computer Supported Cooperative Work (ECSCW'15). Springer, 243-261. DOI :

http://dx . doi . org/10 . 1007/978-3-319-20499-4_13

48. Harvey Sacks. 1984. Notes on Methodology. In Structures of Social Action: Studies in Conversation Analysis, John Maxwell Atkinson and John Heritage (Eds.). Cambridge University Press, 21-27.

49. Harvey Sacks, Emanuel A. Schegloff, and Gail Jefferson. 1974. A Simplest Systematics for the Organization of Turn-Taking for Conversation. Language 50, 4 (Dec. 1974), 696. DOI : http://dx. doi . org/10.2307/412243

50. Allison Sauppé and Bilge Mutlu. 2014. How social cues shape task coordination and communication. In Proceedings of the 17th ACM Conference on Computer Supported Cooperative Work \& Social Computing (CSCW'14). ACM, New York, NY, USA, 97-108. DOI : http://dx.doi.org/10.1145/2531602.2531610

51. Carla Seddon. 2011. Lifestyles and Social Participation. Office for National Statistics.

52. Lara Srivastava. 2005. Mobile phones and the evolution of social behaviour. Behaviour \& Information Technology 24, 2 (March 2005), 111-129. DOI:

http: //dx . doi . org/10 . 1080/01449290512331321910

53. Norman Makoto Su and Lulu Wang. 2015. From Third to Surveilled Place: The Mobile in Irish Pubs. In Proceedings of the 33rd Annual ACM Conference on Human Factors in Computing Systems (CHI'15). ACM, New York, NY, USA, 1659-1668. DOI : http://dx. doi . org/10.1145/2702123.2702574

54. Peter Tolmie, Andy Crabtree, Tom Rodden, and Steve Benford. 2008. "Are You Watching This Film or What?" Interruption and the Juggling of Cohorts. In Proceedings of the 2008 ACM Conference on Computer Supported Cooperative Work (CSCW '08). ACM, New York, NY, USA, 257-266. DOI : http: //dx . doi . org/10.1145/1460563.1460605

55. Sherry Turkle. 2011. Alone Together. Basic Books.

56. Ran Wei and Louis Leung. 1999. Blurring public and private behaviors in public space: policy challenges in the use and improper use of the cell phone. Telematics and Informatics 16, 1-2 (Feb. 1999), 11-26. DOI : http: //dx. doi .org/10.1016/S0736-5853(99)00016-7

57. Ran Wei and Ven-Hwei Lo. 2006. Staying connected while on the move: Cell phone use and social connectedness. New Media \& Society 8, 1 (Feb. 2006), 53-72. DOI : http://dx. doi . org/10 . 1177/1461444806059870 